\title{
cmaJOPEN
}

\section{Prevalence of and risk factors for excess weight gain in pregnancy: a cross-sectional study using survey data}

\author{
Jamie L. Benham MD PhD, Jane E. Booth MSc, Lois E. Donovan MD, Alexander A. Leung MD MPH, \\ Ronald J. Sigal MD MPH, Doreen M. Rabi MD MSc
}

Abstract

Background: Maternal weight gain during pregnancy is required for fetal development; however, excess gestational weight gain is associated with increased maternal and neonatal morbidity. We aimed to determine the proportion of Canadian women who gained excess weight during pregnancy and to identify risk factors for excess gestational weight gain.

Methods: Self-reported data on maternal weight gain were collected from the 2015/16 and 2017/18 cycles of the Canadian Community Health Survey (CCHS), a cross-sectional population-based survey. We included females aged 15 to 54 years with data on height, prepregnancy weight and gestational weight gain. We defined excess gestational weight gain in terms of preconception body mass index (BMI) according to the 2009 guideline of the US Institute of Medicine. We used logistic regression to evaluate potential risk factors for excess gestational weight gain.

Results: Of 1335615 Canadian women (weighted from approximately 9300 survey respondents), 422043 (32\%) gained excess weight during pregnancy. Women with obesity had 33\% lower odds of gaining excess weight relative to women with overweight (odds ratio $0.67,95 \%$ confidence interval $0.48-0.94$ ). Risk factors for excess gestational weight gain were lower education level, white or Indigenous identity, smoking, mood disorder, anxiety disorder and Canadian citizenship.

Interpretation: One-third of Canadian women in this survey had excess gestational weight gain during pregnancy, and women with obesity had lower odds of gaining excess weight during pregnancy relative to women with overweight. Strategies are needed to reduce the proportion of Canadian women who gain excess weight during pregnancy, regardless of preconception BMI.

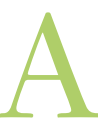

lthough maternal weight gain in pregnancy is vital to fetal development, excess gestational weight gain is associated with adverse pregnancy-related outcomes for mothers and neonates, including gestational hypertension, cesarean delivery and large-for-gestationalage neonates. ${ }^{1-4}$ In addition, the effects of excess gestational weight gain can affect the mother across the lifetime, with postpartum weight retention, excess weight gain in subsequent pregnancies and obesity leading to increased cardiometabolic risk. ${ }^{5-9}$ Excess gestational weight gain can be associated with overweight and obesity in the offspring and associated cardiometabolic sequelae. ${ }^{10}$

In 2009, the US Institute of Medicine updated its recommendations for gestational weight gain to reflect the changing demographic profile of women entering pregnancy, including older women and women with more excess weight. ${ }^{11}$ This guideline provides specific gestational weight gain recommendations for each body mass index (BMI) category. ${ }^{12}$ These recommendations were designed to reduce adverse maternal and neonatal outcomes associated with insufficient and excess gestational weight gain. ${ }^{11,12}$ Data from the 2006/07 Statistics Canada Maternity Experiences Survey showed that $48.7 \%$ of Canadian women gained excess weight during pregnancy, in terms of the 2009 Institute of Medicine guideline. ${ }^{13}$ The extent to which Canadian women have gained more than the recommended upper limit for gestational weight gain since the current Institute of Medicine guideline was published is unknown.

Our primary objective was to determine the proportion of Canadian women who gain excess weight during pregnancy using data from a nationally representative cross-sectional survey. Our secondary objective was to identify risk factors for excess gestational weight gain.

\section{Competing interests: None declared.}

This article has been peer reviewed.

Correspondence to: Jamie Benham, jlbenham @ucalgary.ca CMAJ Open 2021 December 14. DOI:10.9778/cmajo.20200276 


\section{Methods}

\section{Study design, setting and participants}

For this analysis, we used data from the 2015/16 and 2017/18 cycles of the Canadian Community Health Survey (CCHS). Detailed information regarding the CCHS data sources, methodology and data accuracy has been previously published. ${ }^{14}$ In brief, the CCHS is a national cross-sectional survey designed to provide population estimates on the health status of Canadians. The target population was Canadians 12 years of age or older who lived in private occupied dwellings in all provinces and territories (about 97\% of the Canadian population). The CCHS excludes persons living on reserves or in other Indigenous settlements, persons who are institutionalized and full-time members of the Canadian Armed forces, which together represent less than $3 \%$ of the Canadian population 12 years of age and older. A multistage sample allocation strategy was employed to select participants in the CCHS. Participation was voluntary.

For the current cross-sectional study, we included CCHS respondents aged 15 to 54 years who reported giving birth in the 5 years before survey administration. We excluded participants if data were missing on height, prepregnancy weight or weight gain during the most recent pregnancy.

\section{Excess gestational weight gain}

Survey respondents self-reported height and prepregnancy weight, from which we calculated BMI. We adjusted the calculated BMI using a correction formula (corrected BMI = $-0.12+1.05 \times \mathrm{BMI})^{15}$ from reported and measured values in previously administered surveys, to minimize potential misclassification bias. This correction reduces discordance between self-reported BMI and objective measures, particularly for the lowest and highest BMI categories, and thus leads to improved estimates for the prevalence of obesity. ${ }^{15}$

We then classified participants according to prespecified BMI categories: underweight, BMI less than 18.5; normal weight, BMI 18.5 to 24.9; overweight, BMI 25 to 29.9; and obese, BMI 30 or above. We classified respondents as gaining excess gestational weight during their most recent pregnancy if they reported gaining more than the recommended upper limit for their preconception BMI, consistent with the Institute of Medicine guideline: ${ }^{11}$ underweight, gain of more than $18.2 \mathrm{~kg}$; normal weight, gain of more than $15.9 \mathrm{~kg}$; overweight, gain of more than $11.4 \mathrm{~kg}$; and obese, gain of more than $9.1 \mathrm{~kg}$.

\section{Potential risk factors}

Potential risk factors for excess gestational weight gain include younger age, higher preconception BMI, lower socioeconomic status, smoking, being a recent immigrant and a history of anxiety, mood disorders or diabetes. ${ }^{16-19}$ The demographic characteristics that we assessed in this study were age ( $<35 \mathrm{yr}, \geq 35 \mathrm{yr}$ ), area of residence (urban, rural), citizenship status (Canadian citizen, landed immigrant, not a permanent resident), province or territory, education level (less than secondary education, secondary education, postsecondary education), household income $(<\$ 50000, \$ 50$ 000-\$99 999,
$\$ 100$ 000-\$149 999, $\geq \$ 150$ 000) and self-identified race or ethnicity (Indigenous, white, Black, Latin American, Southeast Asian, other). We coded the history of each of mood disorder, anxiety disorder or diabetes mellitus (type 1 or type 2) dichotomously as present or absent. We also evaluated behaviours during pregnancy, specifically smoking, consuming alcohol and taking supplements containing folic acid, as potential risk factors. We coded these behaviour variables dichotomously as any or no consumption during pregnancy.

\section{Statistical analysis}

We obtained population-representative estimates by applying respondent-specific survey weights and bootstrap techniques. Statistics Canada uses sampling weights to ensure that estimates using the collected survey data are representative of the general population of provincial Canada. ${ }^{20}$ The sampling weights are calculated to offset design characteristics, including unequal selection probabilities, extreme values, nonresponse at the personal and household level, and removal of out-of-scope units. Overall, the response rate for the CCHS was $110095(57.5 \%)$ for the 2015/16 ${ }^{21}$ cycle and 113735 $(60.8 \%)$ for the $2017 / 18$ cycle. $^{20}$

To account for clustering in the sampling procedure, we used a set of 1000 replicate bootstrap weights to estimate $95 \%$ confidence intervals (CIs).$^{20}$ Item-level missing data for the variables of interest were minimal. We did not use imputation methods.

We calculated descriptive statistics (percentage frequencies) for all participant characteristics and risk factors for excess gestational weight gain. ${ }^{20} \mathrm{We}$ used multivariable logistic regression to assess the odds ratios (ORs) for the odds of gaining excess gestational weight compared with the odds of not gaining excess gestational weight, adjusted for BMI and age for each of the potential risk factors for excess gestational weight gain independently. We report the OR for each logistic regression with the associated $95 \%$ CI. We excluded participants with missing data on any specific variable from analyses involving that variable.

We performed all analyses with Stata Statistical Software (StataCorp, version 14). The level of statistical significance was predetermined as $p<0.05$.

\section{Ethics approval}

The study was based on publicly accessible data from Statistics Canada, which were exempt from research ethics board review.

\section{Results}

Approximately 9300 individuals representing 1335615 Canadian women were eligible for inclusion in this study (Figure 1). Demographic, socioeconomic, maternal and pregnancy-related characteristics are presented in Table 1. Overall, 422043 $(32 \%)$ women gained more weight than recommended by the Institute of Medicine based on their preconception BMI. The mean age of women who gained excess weight during pregnancy was 32.6 (95\% CI 32.3-32.9) years compared with 33.4 (95\% CI 33.2-33.6) years for women who did not gain excess weight in pregnancy. 


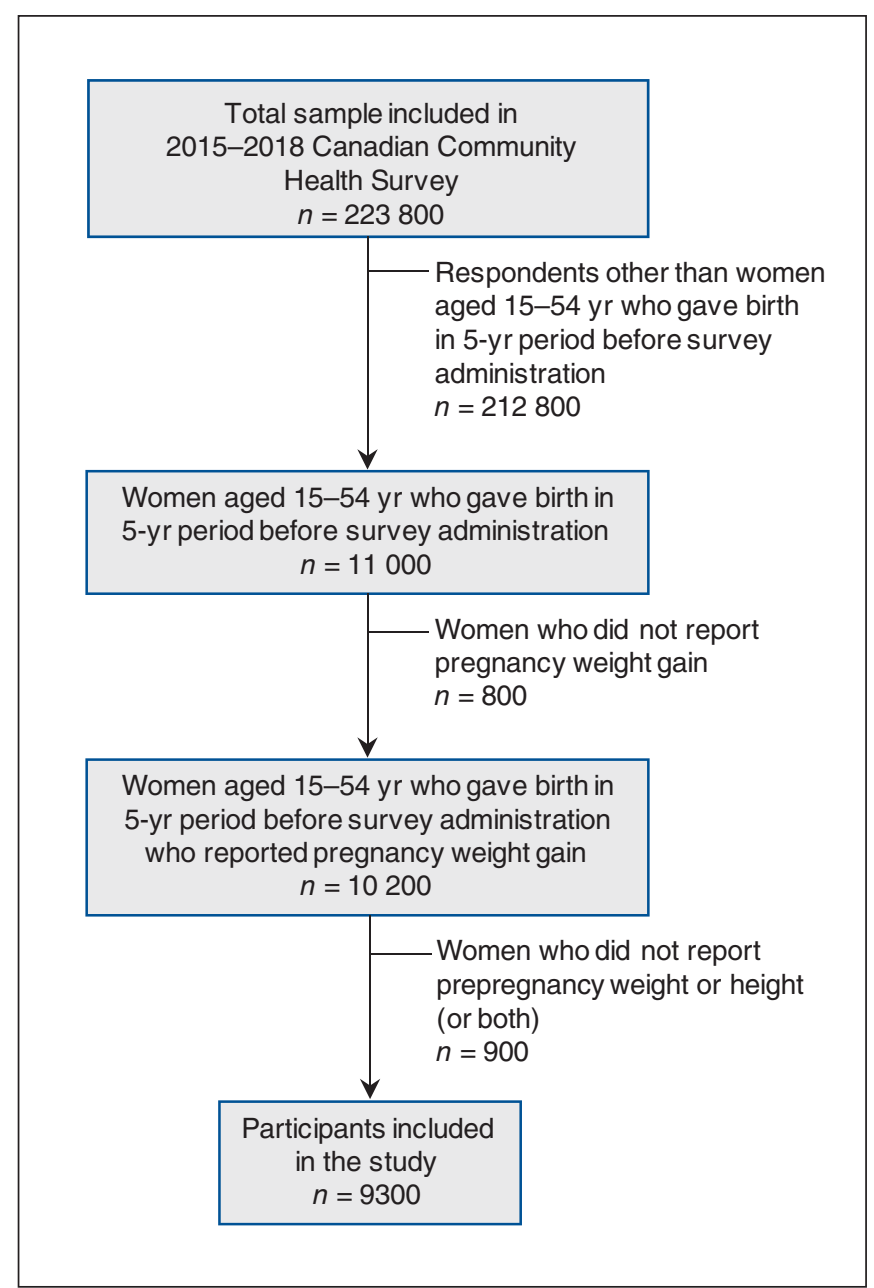

Figure 1: Participant flow diagram for the Canadian Community Health Survey, 2015-2018. Values shown are unweighted frequencies, with numbers rounded to the nearest 100 according to Statistics Canada requirements. ${ }^{20}$

Overall, mean weight gain during pregnancy for all included women was 15.9 (95\% CI 15.4-16.5) kg. Mean weight gain by BMI category was 17.5 (95\% CI 15.0-20.0) $\mathrm{kg}$ for women with BMI less than 18.5, 17.3 (95\% CI 16.4-18.1) $\mathrm{kg}$ for women with BMI 18.5 to $24.9,15.2$ (95\% CI $14.3-16.1) \mathrm{kg}$ for women with BMI 25 to 29.9, and 12.2 (95\% CI 11.0-13.3) for women with BMI of 30 or above.

\section{Factors associated with excess weight gain}

Women with obesity had $33 \%$ lower odds of gaining excess weight compared with women with overweight (OR 0.67, 95\% CI 0.48-0.94). The odds of having excess weight gain were similar in those who were younger than 35 years and those who were 35 or older. A medical history of mood disorder or anxiety disorder was associated with increased odds of gaining excess weight during pregnancy compared with not having a history of these medical conditions. Smoking during pregnancy was associated with excess gestational weight gain compared with not smoking (OR 1.36, 95\% CI 1.03-1.81). Age, history of type 1 or type 2 diabetes, alcohol consumption and folic acid intake during pregnancy were not associated with excess weight gain.

Sociodemographic factors associated with excess weight gain in pregnancy included citizenship status, education level, and race or ethnicity. Compared with women who reported being Canadian citizens, women who reported their citizenship status as landed immigrants (OR 0.61, 95\% CI 0.51-0.74) or not a permanent resident (OR 0.51, 95\% CI 0.29-0.92) had lower odds of gaining excess weight during pregnancy. Women who had a postsecondary certificate or degree had lower odds of gaining excess gestational weight than women who did not (OR $0.72,95 \%$ CI $0.53-0.97$ ). Women who identified as white had higher odds of excess gestational weight gain than women who did not identify as white (OR $1.38,95 \%$ CI $1.17-1.64)$, as did women who identified as Indigenous compared with women who did not identify as Indigenous (OR 1.44, 95\% CI 1.09-1.89). Women of South Asian, Chinese, Filipino, Arab, West Asian, Korean, Japanese or more than 1 ethnic origin had 36\% lower odds of excess gestational weight gain than women who identified as white (OR 0.64, 95\% CI 0.51-0.81). Household income, province or territory of residence, and rural versus urban location were not associated with excess gestational weight gain.

\section{Interpretation}

The findings from this study indicate that nearly one-third of Canadian women gained more weight than recommended during pregnancy according to the Institute of Medicine criteria. ${ }^{11}$ Among Canadian women, the prevalence of excess gestational weight gain, according to these criteria, has declined within the last decade, from an estimate of $48.7 \%$ using data from the 2005/06 Statistics Canada Maternity Experiences Survey ${ }^{13}$ to our estimate of $32 \%$ using data collected between 2015 and 2018, especially among women with obesity. Although this is an encouraging trend, almost one-third of Canadian women continue to gain more than the recommended amount of weight during pregnancy and are therefore at increased risk for associated maternal and neonatal complications, ${ }^{2,3}$ increased postpartum weight retention,, 56 further cumulative weight gain with subsequent pregnancies ${ }^{22}$ and cardiometabolic disease associated with obesity. 8,9

Our estimate for excess gestational weight gain is lower than most previously reported estimates.,13,23-29 There are likely 2 major reasons for these differences. Studies that adjusted for gestational age have consistently reported a $10 \%$ to $15 \%$ higher frequency of excess gestational weight gain than those that did not make such adjustments, ${ }^{13,29-31}$ including the present study.

Although previous studies have generally indicated that obese women were more likely to gain excess gestational weight than those with normal BMI before conception, ${ }^{13,16,23,24,26,27,32-34}$ there has been a reversal in this association in the last decade, ${ }^{35,36}$ coinciding with the release of the Institute of Medicine guideline in $2009^{11}$ and also confirmed by our findings. This may reflect improvements in counselling for pregnant 


\begin{tabular}{|c|c|c|c|c|}
\hline \multirow[b]{2}{*}{ Characteristic* $^{*}$} & \multirow{2}{*}{$\begin{array}{l}\text { No.† (\%) of all } \\
\text { respondents }\end{array}$} & \multicolumn{2}{|c|}{$\begin{array}{l}\text { Excess weight gain; } \\
\text { no. }(\%) \text { of respondentsł }\end{array}$} & \multirow{2}{*}{$\begin{array}{l}\text { Adjusted ORß } \\
\qquad(95 \% \mathrm{Cl})\end{array}$} \\
\hline & & No & Yes & \\
\hline All women included in study & 1335615 & $913572(68)$ & $422043(32)$ & - \\
\hline \multicolumn{5}{|l|}{ Age, yr } \\
\hline$\geq 35$ & 425567 (32) & $302677(71)$ & $122890(29)$ & 1.00 (ref.) \\
\hline$<35$ & $910048(68)$ & $610895(67)$ & $299153(33)$ & $1.12(0.88-1.43)$ \\
\hline \multicolumn{5}{|l|}{ BMI } \\
\hline$<18.5$ & $52559(4)$ & 33362 (63) & $19197(37)$ & $0.93(0.55-1.56)$ \\
\hline $18.5-24.9$ & $739362(55)$ & $487685(66)$ & $251677(34)$ & $0.95(0.75-1.21)$ \\
\hline $25-29.9$ & $327007(24)$ & $221353(68)$ & $105654(32)$ & 1.00 (ref.) \\
\hline$\geq 30$ & $216687(16)$ & $171171(79)$ & $45516(21)$ & $0.67(0.48-0.94)$ \\
\hline \multicolumn{5}{|l|}{ Rurality } \\
\hline Living in a rural community & $220460(17)$ & $150738(68)$ & $69722(32)$ & 1.00 (ref.) \\
\hline Living in an urban community & $1115155(83)$ & $762834(68)$ & $352321(32)$ & $1.00(0.86-1.16)$ \\
\hline \multicolumn{5}{|l|}{ Citizenship status } \\
\hline Canadian citizen & $906142(68)$ & $595541(66)$ & 310601 (34) & 1.00 (ref.) \\
\hline Landed immigrant & $361008(27)$ & 269735 (75) & $91273(25)$ & $0.61(0.51-0.74)$ \\
\hline Not a permanent resident & 38575 (3) & $30162(78)$ & $8413(22)$ & $0.51(0.29-0.92)$ \\
\hline Not stated & $29890(2)$ & $18134(61)$ & $11756(39)$ & - \\
\hline \multicolumn{5}{|l|}{ Province or territory } \\
\hline British Columbia & $154489(12)$ & $108013(70)$ & $46476(30)$ & 1.00 (ref.) \\
\hline Alberta & $184882(14)$ & $128611(70)$ & $56271(30)$ & $1.02(0.79-1.31)$ \\
\hline Saskatchewan & 45897 (3) & $31033(68)$ & $14864(32)$ & $1.09(0.79-1.51)$ \\
\hline Manitoba & $51182(4)$ & 34438 (67) & $16744(33)$ & $1.14(0.83-1.56)$ \\
\hline Ontario & 489425 (37) & $331731(68)$ & $157694(32)$ & $1.13(0.88-1.44)$ \\
\hline Quebec & 322111 (24) & $218648(68)$ & $103463(32)$ & $1.09(0.85-1.40)$ \\
\hline New Brunswick & $26750(2)$ & $18963(71)$ & $7787(29)$ & $0.96(0.64-1.43)$ \\
\hline Nova Scotia & $32174(2)$ & $21398(67)$ & $10776(33)$ & $1.19(0.83-1.71)$ \\
\hline Prince Edward Island & $4800(<1)$ & $3434(72)$ & $1366(28)$ & $1.00(0.60-1.64)$ \\
\hline Newfoundland and Labrador & $18046(1)$ & $12754(71)$ & $5292(29)$ & $0.99(0.64-1.52)$ \\
\hline Yukon Territory & $1530(<1)$ & $1162(76)$ & $368(24)$ & $0.74(0.41-1.32)$ \\
\hline Northwest Territories & $2602(<1)$ & $2034(78)$ & $568(22)$ & $0.67(0.37-1.22)$ \\
\hline Nunavut & $1725(<1)$ & $1351(78)$ & $374(22)$ & $0.57(0.28-1.15)$ \\
\hline \multicolumn{5}{|l|}{ Race or ethnicity } \\
\hline White & $851833(64)$ & $565345(66)$ & $286488(34)$ & $1.38(1.17-1.64)$ \\
\hline Indigenous & $71747(5)$ & $43601(61)$ & $28146(39)$ & $1.44(1.09-1.89)$ \\
\hline Black & $49849(4)$ & $37082(74)$ & $12767(26)$ & $0.77(0.49-1.20)$ \\
\hline Latin American & $25117(2)$ & $18910(75)$ & $6208(25)$ & $0.74(0.40-1.36)$ \\
\hline Southeast Asian & $20726(2)$ & $15212(73)$ & $5514(27)$ & $0.71(0.34-1.48)$ \\
\hline Otherq & $316343(24)$ & $233422(74)$ & $82920(26)$ & $0.64(0.51-0.81)$ \\
\hline \multicolumn{5}{|l|}{ Highest level of education } \\
\hline Less than secondary education & $79241(6)$ & $47816(60)$ & $31425(40)$ & 1.00 (ref.) \\
\hline Completed secondary education & $227086(17)$ & $149996(66)$ & $77090(34)$ & $0.83(0.61-1.13)$ \\
\hline Completed postsecondary certificate/degree & $1022021(77)$ & $710716(70)$ & 311305 (30) & $0.72(0.53-0.97)$ \\
\hline Not stated & 7267 (1) & $5044(69)$ & $2223(31)$ & - \\
\hline
\end{tabular}




\begin{tabular}{|c|c|c|c|c|}
\hline \multirow[b]{2}{*}{ Characteristic* $^{*}$} & \multirow{2}{*}{$\begin{array}{l}\text { No.† (\%) of all } \\
\text { respondents }\end{array}$} & \multicolumn{2}{|c|}{$\begin{array}{l}\text { Excess weight gain; } \\
\text { no. }(\%) \text { of respondents } \neq\end{array}$} & \multirow{2}{*}{$\begin{array}{l}\text { Adjusted OR§ } \\
\qquad(95 \% \mathrm{Cl})\end{array}$} \\
\hline & & No & Yes & \\
\hline \multicolumn{5}{|l|}{ Household income, \$ } \\
\hline$<50000$ & $344270(26)$ & $229490(67)$ & $114780(33)$ & 1.00 (ref.) \\
\hline $50000-99999$ & $428113(32)$ & $295512(69)$ & $132601(31)$ & $0.96(0.81-1.41)$ \\
\hline 100 000-149999 & 311770 (23) & 212049 (68) & 99721 (32) & $1.00(0.81-1.23)$ \\
\hline$\geq 150000$ & $251462(19)$ & $176521(70)$ & $74941(30)$ & $0.90(0.73-1.12)$ \\
\hline \multicolumn{5}{|l|}{ Maternal medical conditions } \\
\hline Anxiety & $145880(11)$ & $88453(61)$ & $57427(39)$ & $1.52(1.23-1.87)$ \\
\hline Mood disorder & $129239(10)$ & $80010(62)$ & 49229 (38) & $1.38(1.11-1.71)$ \\
\hline Diabetes mellitus (type 1 or type 2) & $23791(2)$ & $17631(74)$ & $6160(26)$ & $0.89(0.52-1.50)$ \\
\hline \multicolumn{5}{|l|}{ Smoked during pregnancy } \\
\hline Yes & $65535(5)$ & $39665(61)$ & $25870(39)$ & $1.36(1.03-1.81)$ \\
\hline No & $1269378(95)$ & $873742(69)$ & $395637(31)$ & 1.00 (ref.) \\
\hline Not stated & $702(<1)$ & $165(24)$ & $537(76)$ & $6.99(0.78-62.70)$ \\
\hline \multicolumn{5}{|l|}{ Used alcohol during pregnancy } \\
\hline Yes & 33495 (3) & $23861(71)$ & $9634(29)$ & $0.88(0.56-1.39)$ \\
\hline No & $1301614(97)$ & $889290(68)$ & $412325(32)$ & 1.00 (ref.) \\
\hline Not stated & $506(<1)$ & $421(83)$ & $85(17)$ & $0.35(0.06-2.03)$ \\
\hline \multicolumn{5}{|l|}{ Took folic acid during pregnancy } \\
\hline Yes & 1194639 (89) & $812113(68)$ & $382526(32)$ & $1.24(0.94-1.63)$ \\
\hline No & $128989(10)$ & 92849 (72) & $36140(28)$ & 1.00 (ref.) \\
\hline Not stated & $11987(1)$ & $8609(72)$ & $3378(28)$ & $0.98(0.49-1.49)$ \\
\hline \multicolumn{5}{|c|}{$\begin{array}{l}\text { Note: } \mathrm{BMI}=\text { body mass index, } \mathrm{Cl}=\text { confidence interval, } \mathrm{OR}=\text { odds ratio, ref. = reference category. } \\
\text { “All characteristics were self-reported by respondents to the Canadian Community Health Survey (or were derived from self-reported data). } \\
\text { †Sample size is estimated using population weights. } \\
\text { fPercentages under "No" and "Yes" headings are calculated across rows (i.e., in relation to the value in the first numeric column of each row). } \\
\text { §The odds of gaining excess gestational weight compared with the odds of not gaining excess gestational weight, adjusted for BMl and age. } \\
\text { q"Other" incorporates participant responses of South Asian, Chinese, Filipino, Arab, West Asian, Korean, Japanese, other or more than } 1 \text { racial origin. }\end{array}$} \\
\hline
\end{tabular}

women with obesity coinciding with the publication within the last decade of several relevant clinical practice guidelines. ${ }^{37}$ These guidelines have specifically addressed the management of pregnancy in women with obesity, including recommendations for education about the risks associated with obesity and recommendations for gestational weight gain consistent with the 2009 Institute of Medicine guideline. ${ }^{37}$ Given that the risks of excess gestational weight gain affect all women during pregnancy, ${ }^{1,2}$ concerted efforts should be made to address weight gain in all women, regardless of preconception BMI.

Although there have been some small differences among studies in the reported frequencies of excess weight gain, the general direction of findings has been highly consistent, showing that at least one-third and upward of one-half of all pregnancies in Canada are associated with potentially unhealthy amounts of weight gain. Pregnancy has been identified as a trigger for cumulative weight gain in the life course of a woman, ${ }^{22,38}$ but many women are not aware of gestational weight gain recommendations..$^{39,40}$ Studies of Canadian health care providers ${ }^{41,42}$ and women receiving care during pregnancy ${ }^{33,43-45}$ reveal a discordance between the proportion of health care providers who report making recommendations about gestational weight gain and the information that women report receiving. One survey found that $95 \%$ of health care providers reported counselling pregnant women about gestational weight gain, ${ }^{41}$ whereas between $5 \%$ and $50 \%$ of pregnant women recall receiving counselling on appropriate gestational weight gain. ${ }^{43,45}$

An opportunity to improve women's health is being missed in antenatal care; this gap needs to be addressed to ensure that all women receive effective counselling with respect to healthy weight gain throughout pregnancy. Furthermore, women who are informed of the recommendations for gestational weight gain are often not given strategies that have been shown to reduce the risk of excess weight gain, ${ }^{33}$ including motivational interviewing ${ }^{46}$ and behavioural interventions, such as education, exercise ${ }^{47}$ and diet. ${ }^{48}$ Although it may not be feasible to offer in-person interventions to all 
women during pregnancy, targeted interventions for women with characteristics that make them more susceptible to excess gestational weight gain, who may benefit the most, might be considered.

\section{Limitations}

The strengths of this study include the use of a large sample that is nationally representative of the general population of provincial Canada.

This study had several limitations. Weight and height were self-reported, potentially leading to misclassification, as women often underestimate their preconception weight. ${ }^{49}$ This could in turn result in an underestimation of the proportion of women who gained excess gestational weight secondary to participants being classified in a lower BMI category, with a higher cut-off for gestational weight gain. Another consideration is that women with obesity have been found to underreport their gestational weight gain, ${ }^{49}$ which could lead to further underestimation of the proportion of excess gestational weight gain.

Given Statistics Canada's policy limiting the release of data if the number of sampled respondents in a cell is less than $35,{ }^{20}$ we were unable to analyze each of the risk factors by BMI class to determine whether risk factors varied by BMI class. There also may have been recall bias, as women were asked to report the amount of weight gained in a pregnancy that occurred up to 5 years prior, and therefore the data may be less reliable.

Potential confounders that we could not evaluate included frequency of prenatal visits and type of care provider (i.e., family physician, obstetrician, midwife), which could affect the proportion of women who gained excess weight, if increased education and monitoring of gestational weight gain led to more appropriate weight gain. Another potential confounder that we were unable to evaluate was gestational age, as these data were not collected. Women who gave birth before term (i.e., < 37 wk gestational age) would have had less time to gain excess gestational weight, ${ }^{30}$ and the inclusion of these women would lead to underestimation of the proportion of women who gained excess weight during pregnancy.

Several other risk factors for excess gestational weight gain have been identified in the literature, such as lower selfefficacy, ${ }^{50}$ higher parity, ${ }^{13,27,32}$ lower physical activity during pregnancy ${ }^{27}$ and less advice from health care providers. ${ }^{32} \mathrm{We}$ were unable to evaluate these potential risk factors because such questions were not administered in the CCHS. ${ }^{14}$

\section{Conclusion}

About one-third of Canadian women gained more weight during pregnancy than is recommended. Identified risk factors for excess gestational weight gain were lower education level, white or Indigenous identity, smoking, mood disorder, anxiety disorder and Canadian citizenship. Although a lower proportion of women gained excess weight compared with a decade earlier, a considerable number of women continued to be at risk not only for pregnancy-associated complications, but also for weight retention, diabetes and future cardiometabolic complications related to overweight and obesity.
The Institute of Medicine clinical guideline has been helpful in so far as it has outlined clear targets for gestational weight gain; however, more needs to be done to ensure that women can be successful in achieving appropriate weight gain in pregnancy. Future studies are needed to determine whether these targets are being achieved. Effective, acceptable and accessible strategies to encourage healthy weight gain during pregnancy are available and should be implemented more broadly and used specifically in high-risk groups.

\section{References}

1. Faucher MA, Barger MK. Gestational weight gain in obese women by class of obesity and select maternal/newborn outcomes: a systematic review. Women Birth 2015;28:e70-9.

2. Crane JM, White J, Murphy P, et al. The effect of gestational weight gain by body mass index on maternal and neonatal outcomes. 7 Obstet Gynaecol Can 2009;31:28-35.

3. Johnson J, Clifton RG, Roberts JM, et al.; Eunice Kennedy Shriver National Institute of Child Health and Human Development (NICHD) MaternalFetal Medicine Units (MFMU) Network. Pregnancy outcomes with weight gain above or below the 2009 Institute of Medicine guidelines. Obstet Gynecol 2013;121:969-75.

4. Gaillard R, Durmus B, Hofman A, et al. Risk factors and outcomes of maternal obesity and excessive weight gain during pregnancy. Obesity (Silver Spring) 2013;21:1046-55.

5. Amorim AR, Rössner S, Neovius M, et al. Does excess pregnancy weight gain constitute a major risk for increasing long-term BMI? Obesity (Silver Spring) 2007;15:1278-86.

6. Nehring I, Schmoll S, Beyerlein A, et al. Gestational weight gain and long-term postpartum weight retention: a meta-analysis. Am f Clin Nutr 2011;94:1225-31.

7. Linné Y, Rössner S. Interrelationships between weight development and weight retention in subsequent pregnancies: the SPAWN study. Acta Obstet Gynecol Scand 2003;82:318-25.

8. McClure CK, Catov JM, Ness R, et al. Associations between gestational weight gain and BMI, abdominal adiposity, and traditional measures of cardiometabolic risk in mothers 8 y postpartum. Am 7 Clin Nutr 2013;98:1218-25.

9. Rooney BL, Schauberger CW. Excess pregnancy weight gain and long-term obesity: one decade later. Obstet Gynecol 2002;100:245-52.

10. Gaillard R, Steegers EA, Franco OH, et al. Maternal weight gain in different periods of pregnancy and childhood cardio-metabolic outcomes. The Generation R Study. Int 7 Obes (Lond) 2015;39:677-85.

11. Institute of Medicine; National Research Council. Weight gain during pregnancy: reexamining the guidelines. Washington (DC): The National Academies Press; 2009.

12. Institute of Medicine. Nutrition during pregnancy: Part I - Weight gain, Part II Nutrient supplements. Washington (DC): The National Academy Press; 1990.

13. Kowal C, Kuk J, Tamim H. Characteristics of weight gain in pregnancy among Canadian women. Matern Child Health 7 2012;16:668-76.

14. Canadian Community Health Survey: annual component (CCHS). Ottawa: Statistics Canada; modified 2020 Jan. 2. Available: https://www23.statcan.gc.ca/ imdb/p2SV.pl? Function=getSurvey\&SDDS=3226 (accessed 2020 Oct. 9).

15. Dzakpasu S, Duggan J, Fahey J, et al. Estimating bias in derived body mass index in the Maternity Experiences Survey. Health Promot Chronic Dis Prev Can 2016; 36:185-93.

16. Restall A, Taylor RS, Thompson JMD, et al. Risk factors for excessive gestational weight gain in a healthy, nulliparous cohort. 7 Obes 2014;2014:148391.

17. Campbell EE, Dworatzek PDN, Penava D, et al. Factors that influence excessive gestational weight gain: moving beyond assessment and counselling. 7 Matern Fetal Neonatal Med 2016;29:3527-31.

18. Kapadia MZ, Gaston A, Van Blyderveen S, et al. Psychological antecedents of excess gestational weight gain: a systematic review. BMC Pregnancy Childbirth 2015;15:107.

19. Scifres CM, Feghali MN, Althouse AD, et al. Effect of excess gestational weight gain on pregnancy outcomes in women with type 1 diabetes. Obstet Gynecol 2014;123:1295-302.

20. Canadian Community Health Survey (CCHS): public use microdata file, 2017/2018. Ottawa: Statistics Canada; 2019.

21. Canadian Community Health Survey (CCHS): public use microdata file, 2015/2016. Ottawa: Statistics Canada; 2017.

22. Linné Y, Dye L, Barkeling B, et al. Weight development over time in parous women - the SPAWN study - 15 years follow-up. Int 7 Obes Relat Metab Disord 2003;27:1516-22.

23. Chung JGY, Taylor RS, Thompson JM, et al. Gestational weight gain and adverse pregnancy outcomes in a nulliparous cohort. Eur 7 Obstet Gynecol Reprod Biol 2013;167:149-53.

24. Park S, Sappenfield WM, Bish C, et al. Assessment of the Institute of Medicine recommendations for weight gain during pregnancy: Florida, 2004-2007. Matern Child Health 7 2011;15:289-301. 
25. Durie DE, Thornburg LL, Glantz JC. Effect of second-trimester and thirdtrimester rate of gestational weight gain on maternal and neonatal outcomes. Obstet Gynecol 2011;118:569-75.

26. Woolcott C, Dodds L, Ashley-Martin J, et al. Distribution of pregnancyrelated weight measures. Can Fam Physician 2016;62:e400-6.

27. Herring SJ, Nelson DB, Davey A, et al. Determinants of excessive gestational weight gain in urban, low-income women. Womens Health Issues 2012;22: e439-46.

28. Goldstein RF, Abell SK, Ranasinha S, et al. Gestational weight gain across continents and ethnicity: systematic review and meta-analysis of maternal and infant outcomes in more than one million women. BMC Med 2018;16:153.

29. McDonald SD, Woolcott C, Chapinal N, et al. Interprovincial variation in pre-pregnancy body mass index and gestational weight gain and their impact on neonatal birth weight with respect to small and large for gestational age. Can 7 Public Health 2018;109:527-38.

30. Champion ML, Harper LM. Gestational weight gain: update on outcomes and interventions. Curr Diab Rep 2020;20:11.

31. Dzakpasu S, Fahey J, Kirby RS, et al. Contribution of prepregnancy body mass index and gestational weight gain to adverse neonatal outcomes: population attributable fractions for Canada. BMC Pregnancy Childbirth 2015;15:21.

32. Stotland NE, Haas JS, Brawarsky P, et al. Body mass index, provider advice, and target gestational weight gain. Obstet Gynecol 2005;105:633-8.

33. Vinturache A, Winn A, Mannion C, et al. Women's recall of health care provider counselling on gestational weight gain (GWG): a prospective, population-based study. BMC Pregnancy Childbirth 2019;19:136.

34. Begum F, Colman I, McCargar LJ, et al. Gestational weight gain and early postpartum weight retention in a prospective cohort of Alberta women. 7 Obstet Gynaecol Can 2012;34:637-47.

35. Salmon C, Sauve RS, LeJour C, et al. A single gestational weight gain recommendation is possible for all classes of pregnant women with obesity. Obes Res Clin Pract 2020;14:66-72.

36. Enomoto K, Aoki S, Toma R, et al. Pregnancy outcomes based on pre-pregnancy body mass index in Japanese women. PLoS One 2016;11:e0157081.

37. Vitner D, Harris K, Maxwell C, et al. Obesity in pregnancy: a comparison of four national guidelines. 7 Matern Fetal Neonatal Med 2019;32:2580-90.

38. Umberson D, Liu H, Mirowsky J, et al. Parenthood and trajectories of change in body weight over the life course. Soc Sci Med 2011;73:1323-31.

39. Shub A, Huning EYS, Campbell KJ, et al. Pregnant women's knowledge of weight, weight gain, complications of obesity and weight management strategies in pregnancy. BMC Res Notes 2013;6:278.

40. Gaudet LM, Gruslin A, Magee LA. Weight in pregnancy and its implications: what women report. 7 Obstet Gynaecol Can 2011;33:227-34.

41. Ferraro ZM, Boehm KS, Gaudet LM, et al. Counseling about gestational weight gain and healthy lifestyle during pregnancy: Canadian maternity care providers' self-evaluation. Int 7 Womens Health 2013;5:629-36.

42. Lutsiv O, Bracken K, Pullenayegum E, et al. Little congruence between health care provider and patient perceptions of counselling on gestational weight gain. 7 Obstet Gynaecol Can 2012;34:518-24.

43. McDonald SD, Pullenayegum E, Bracken K, et al. Comparison of midwifery, family medicine, and obstetric patients' understanding of weight gain during pregnancy: a minority of women report correct counselling. 7 Obstet Gynaecol Can 2012;34:129-35.
44. Ferraro Z, Rutherford J, Keely EJ, et al. An assessment of patient information channels and knowledge of physical activity and nutrition during pregnancy. Obstet Med 2011;4:59-65.

45. Ledoux T, Van Den Berg P, Leung P, et al. Factors associated with knowledge of personal gestational weight gain recommendations. BMC Res Notes 2015;8:349.

46. Bogaerts AFL, Devlieger R, Nuyts E, et al. Effects of lifestyle intervention in obese pregnant women on gestational weight gain and mental health: a randomized controlled trial. Int 7 Obes (Lond) 2013;37:814-21.

47. Ruchat SM, Mottola MF, Skow RJ, et al. Effectiveness of exercise interventions in the prevention of excessive gestational weight gain and postpartum weight retention: a systematic review and meta-analysis. Br 7 Sports Med 2018;52:1347-56.

48. Walker R, Bennett C, Blumfield M, et al. Attenuating pregnancy weight gain: what works and why - a systematic review and meta-analysis. Nutrients 2018; 10:944.

49. Russell A, Gillespie S, Satya S, et al. Assessing the accuracy of pregnant women in recalling pre-pregnancy weight and gestational weight gain. $f$ Obstet Gynaecol Can 2013;35:802-9.

50. Halili L, Liu RH, Weeks A, et al. High maternal self-efficacy is associated with meeting Institute of Medicine gestational weight gain recommendations. PLoS One 2019;14:e0226301.

Affiliations: Departments of Medicine (Benham, Donovan, Leung, Sigal, Rabi), of Community Health Sciences (Benham, Booth, Leung, Sigal, Rabi), of Obstetrics and Gynecology (Donovan) and of Cardiac Sciences (Sigal, Rabi), Cumming School of Medicine, University of Calgary; Alberta Children's Hospital Research Institute (Donovan), Calgary, Alta.

Contributors: All of the authors conceived and designed the study. Jamie Benham and Jane Booth performed data analysis. Jamie Benham wrote the initial manuscript draft. All of the authors participated in critical revision of the manuscript for important intellectual content, approved the final version for publication and agreed to be accountable for the work.

Funding: No funding was provided for this study.

Content licence: This is an Open Access article distributed in accordance with the terms of the Creative Commons Attribution (CC BY-NC-ND 4.0) licence, which permits use, distribution and reproduction in any medium, provided that the original publication is properly cited, the use is noncommercial (i.e., research or educational use), and no modifications or adaptations are made. See: https://creativecommons.org/licenses/ by-nc-nd/4.0/

Data sharing: Data from the Canadian Community Health Survey are publicly accessible upon request to and approval from Statistics Canada.

Supplemental information: For reviewer comments and the original submission of this manuscript, please see www.cmajopen.ca/content/9/4/ E1168/suppl/DC1. 